\title{
ENTRE DOS EXILIOS: CESARE CIVITA, UN EDITOR ITALIANO EN BUENOS AIRES, DESDE LA GUERRA MUNDIAL HASTA LA DICTADURA MILITAR (1941-1976) ${ }^{1}$
}

POR

EUGENIA SCARZANELLA

Facultad de Ciencias Políticas, Universidad de Bolonia, Italia

El articulo trata de la historia de una editorial argentina, la Editorial Abril creada en 1941 por Cesare Civita, un inmigrante judio que abandonó Italia después de la aprobación de las «leyes raciales». Abril publicaba historietas (El Pato Donald), fotonovelas (Idilio), revistas Femeninas (Claudia) y de actualidad (Panorama). Abril era una empresa familiar que supo utilizar una vasta red de relaciones en la Argentina, Italia y los Estados Unidos. La historia de la Editorial termina con un nuevo exilio de Cesare Civita en 1976. Se utilizan: fuentes de archivo, testimonios, revistas y libros.

Palabras Clave: Argentina, inmigración italiana, exilio, editorial de revistas populares.

Las palabras de Walt Disney: «todo comenzó con un ratón» podrían valer también para empezar a contar la historia de la Editorial Abril, fundada en Buenos Aires en 1941.

Mickey Mouse y Donald Duck son personajes burlones a pesar de haber nacido en una época nada feliz, caracterizada por la crisis económica mundial, por el surgimiento del nazismo y el fascismo y por la Guerra Mundial.

Es en la Italia de Mussolini donde Cesare Civita en 1936 comienza a trabajar en la editorial de Arnoldo Mondadori, editando la publicación de revistas de historietas con los personajes de Walt Disney, famosos gracias a los largometrajes con dibujos animados y a las historias dibujadas.

1 Este ensayo ilustra un aspecto de una investigación más vasta sobre la historia de la editorial Abril en la que estoy trabajando gracias a una financiación de la Universidad de Bolonia. El texto ha sido traducido del italiano por Irene Theiner. 
Tebeos como Topolino (1932), I tre porcellini (1935) y Paperino (1937) consiguen sobrevivir (hasta 1940) a la autarquía impuesta al periodismo para chicos por parte del Ministerio de la Cultura Popular, a pesar de que las aventuras de los simpáticos héroes estadounidenses estuvieran bastante lejos del «espíritu fascista» ${ }^{2}$.

Al promulgarse las leyes raciales en $1938^{3}$, Cesare Civita, judío, se ve obligado a renunciar a su cargo en la editorial ${ }^{4}$. Obtiene a cuenta de la liquidación los derechos sobre las historietas y se traslada a París donde intenta comenzar una nueva actividad, vendiendo las historias de las que era propietario a varios editores para chicos (desde Paul Winkler a Cino del Duca). Experimenta también una nueva fórmula editorial: los cinelibros (bloques que, al hojearlos, daban la impresión de imágenes en movimiento) con personajes de Disney 5 .

Civita obtiene por fin un visado para los Estados Unidos y se traslada a Nueva York inmediatamente después del estallido de la guerra. También ahí, Mickey Mouse y Donald Duck siguen formando parte de sus proyectos de trabajo, de su tenaz reconstrucción de una carrera profesional quebrada por el exilio.

Kay Kamen, a quien Walt Disney en 1934 había encargado la comercialización de Three little pigs y otros personajes de dibujos animados, ayuda a Civita a realizar su proyecto de dirigirse a Sudamérica para vender los derechos Disney $^{6}$ en esa área, aún sin explotar.

Inicia de esta manera la tercera etapa de un exilio que durante casi treinta años convertirá la Argentina en la nueva patria de Civita y su familia y lugar de origen de una extraordinaria empresa, la Editorial Abril.

En este ensayo intentaré focalizar la atención en un aspecto de la historia de la Editorial Abril: el papel de las redes en la creación de la empresa, la ur-

2 Probablemente fue Mussolini mismo quien quiso que se hiciera una excepción para los tebeos de Disney. Genovesi, 1976: 417.

3 Se trata de una serie de medidas legislativas antijudías promulgadas a partir de septiembre de 1938. Véase Sarfatti, 2007: 164-166.

4 Era codirector general de la Editorial.

5 Los cinelibros se realizaban calcando las imágenes de las películas de Disney recibidas en concesión. Se comercializaron en Inglaterra. Brunoro, 2004b.

6 La autorización para utilizar las figuras de Mickey y Minnie Mouse para juguetes, libros y ropa Walt Disney ya la había otorgado en 1931 a George Borgfeld, mientras los derechos para una revista de historietas se cedieron al King Features Syndicate. Véase Eliot, 1993: 92 y 110. M. Sadowski recuerda que Cesare Civita, gracias a sus derechos sobre el Gato Félix, logró obtener una primera importante ganancia en Argentina dado que «empezó a hacer pleitos a toda la gente que hacía imitaciones sin autorización». Germani, 2004:116. Walt Disney visitó Argentina en septiembre de 1941 en ocasión de un viaje organizado por la Oficina de Asuntos Interamericanos durante el cual realizó dos películas: Los tres caballeros y Saludos Amigos. 
dimbre entre iniciativa individual y contactos familiares, políticos, amistosos, étnicos y de negocios en espacios sociales amplios, que casi siempre superan los confines nacionales ${ }^{7}$. Podemos imaginar un entrelazado de hilos que enlazan la red familiar, en el centro de la trama, con la étnica (que es doble: italiana y judía), y también con la de las amistades políticas y profesionales y la de la business community nacional e internacional. Cada una de estas redes, a su vez, está conectada con las otras, fortaleciendo el tejido en el que se apoya la empresa. Forma parte de este tejido también el hilo que une la editorial con el poder gubernamental. Como trataré de demostrar, éste es el punto más débil, el que - al romperse — terminará por hacer jirones la tela.

LOS AÑOS DE LA GUERRA, 1941-1945

La historia de Abril brinda la ocasión para ilustrar algunas cuestiones que forman parte del actual debate sobre el fenómeno migratorio. En primer lugar, la historia de Cesare Civita y de la sociedad que ha creado es un buen punto de partida para repensar el fenómeno del transnacionalismo.

Samuel L. Baily justamente ha subrayado que lo que los estudiosos de fenómenos sociales llaman hoy «transnacionalismo» no es de ninguna manera una característica nueva de las migraciones, sino que es un fenómeno antiguo que está intrínsecamente vinculado a la experiencia migratoria. Analizando el caso argentino, ha mostrado que desde el siglo XIX se pueden identificar «... attività che i migranti conducono a cavallo delle frontiere e che connettono società di origine e di insediamento $\rangle^{8}$.

La historia de Abril no sólo confirma esta observación de Baily, sino que muestra que la red de conexiones que los migrantes establecen es mucho más amplia y no concierne sólo a los espacios de salida y llegada, sino también a otros países. No se debe pensar que esta capacidad de movilizar recursos y mantener relaciones en dirección multipolar sea algo que toca solamente a las élites políticas o empresariales. Como han mostrado Donna Gabaccia y Fraser Ottanelli, incluso los trabajadores siempre han tejido una trama de contactos que involucraba el país de origen y varios países de emigración ${ }^{9}$.

7 Para el concepto de red en sociología véase la introducción de Fortunata Piselli. Piselli, 1995: 3-26.

8 «... actividades que los migrantes llevan a cabo a caballo de las fronteras y que vinculan las sociedades de origen y de asentamiento». Baily, 2005: 47.

9 Gabaccia y Ottanelli, 2001. 
El transnacionalismo, entendido como capacidad de desempeñar diferentes actividades a caballo de las fronteras, se ve acompañado y a menudo se superpone al proceso de formación de redes de relaciones complejas: amistosas, familiares, religiosas, laborales, de negocios. A través de estas redes los individuos y los grupos (y las empresas) acumulan un capital social que utilizan en sus actividades y proyectos.

Quizás en el caso de Cesare Civita más que de transnacionalismo se podría hablar de cosmopolitismo ${ }^{10}$. Él y su familia están en el centro de complejos vínculos, de experiencias en lugares lejanos y de contactos con diferentes culturas. Nacido en New York de padres que temporalmente habían emigrado allí, Cesare Civita y sus hermanos Vittorio y Arturo transcurren períodos en los USA, desarrollando una pasantía en el ámbito de los negocios. Los contactos y el patrimonio de conocimientos que adquieren los llevan luego a Italia y África (a Etiopía, colonia italiana desde 1936).

París y Londres son, luego del abandono de Italia impuesto por las leyes antijudías, los nuevos puntos de referencia, a los que sigue Nueva York.

En Buenos Aires (como en Río de Janeiro, primera etapa de su viaje sudamericano) Cesare Civita encuentra a judíos italianos que como él habían huido del racismo fascista y la guerra. Conoce a italianos emigrados por motivos económicos o políticos en los años anteriores y judíos que pertenecían a una antigua colectividad tanto asquenazí (los así llamadas «rusos») como sefardí.

Es este tejido social, afectivo y económico el que le permite trasladarse definitivamente a Buenos Aires en mayo de 1941 y al poco tiempo, el 21 de noviembre de 1941, fundar junto a dos socios, Alberto Levi y Paolo Terni, a los que se unirán en 1944 Leone Amati y Manuel Diena — todos ellos judíos italianos - una pequeña editorial para la infancia. Su nombre es Abril y su logo es un árbol, símbolos no sólo de juventud, sino también de un nuevo inicio ${ }^{11}$.

El primer producto de Abril son libros para niños destinados a la colección llamada «Pequeños Grandes Libros» que obtiene un gran éxito (un millón de libritos por año) $)^{12}$.

En la colección entran también los personajes de Disney. Pero recién en julio de 1944 Abril obtiene de la sociedad de Burbank la autorización para pu-

10 Para una distinción semántica de los términos, Cohen, 2005: 21-23.

11 En cuanto al origen del nombre véase el testimonio de Boris Spivacow en Spivacow, 1995: 26. Según Civita la elección del nombre se debió también a razones más prosaicas: era una marca aún no registrada. Sobre las políticas argentinas en relación a la inmigración en este periodo: Senkman, 1991.

12 En esa época existían sólo otras dos editoriales especializadas en libros para niños, Editorial Atlántida y Editorial Juventud Argentina. 
blicar un semanario totalmente dedicado a los héroes de los dibujos animados, al que atribuirán como título el nombre del más transgresivo de ellos, El Pato Donald.

El lanzamiento de la revista había sido precedido por una idea publicitaria original. Anticipaba lo que Walt Disney comenzará a cultivar recién al final de la década: la creación de una ciudad habitada por Mickey, Pato Donald, Pinocho, Blancanieves, Bambi. Bárbara Civita, la hija menor de Cesare Civita, recuerda la emoción de caminar por las salas de una Disneyville creada en el corazón de Buenos Aires en el invierno de 1943 y encontrar a los personajes de papel tan queridos ${ }^{13}$.

También la hija mayor Adriana participa enseguida en la aventura de Abril, firmando con su letra infantil las respuestas de Pato Donald a las cartitas que cada vez más niños enviaban al tebeo, un gran éxito desde sus ini$\operatorname{cios}^{14}$. El progresivo aumento de las ventas llegará a una tirada de un millón de ejemplares ${ }^{15}$.

Para la distribución y la impresión Abril escogió dos sociedades creadas por italianos y líderes en el sector, la Vaccaro y Livieri y la Compañía General Fabril Financiera. Esta última era el grupo más importante del empresariado italiano, vinculado, a través de su gerente Vittorio Valdani, al fascismo italiano y simpatizante del nuevo régimen militar que se estableció en Argentina con la revolución de los coroneles de 1943.

El hecho paradójico era que Cesare Civita y la mayor parte de los colaboradores de la editorial eran, por el contrario, antifascistas y nutrían simpatías socialistas. La red de relaciones construida por Civita al llegar a Argentina comprendía, efectivamente, los ambientes italianos antifascistas (Giuseppe Parpagnoli, Gino Germani, Mario Mariani, Paolo Terni, Ugo Ravenna, Renato Ugolini), con quienes había dado origen al semanario «Italia Libre», expresión del antifascismo no comunista ${ }^{16}$.

El transnacionalismo bajo la forma de participación a distancia en la vida política del país de origen se expresaba en este diario y en esta asociación que no se limitaba al ámbito argentino sino que involucraba a italianos emigrados a América del Norte y del Sur.

Civita participaba no sólo en las vicisitudes políticas del país de origen de su familia, sino que también se interesaba en el futuro de la creación y del

13 Testimonio de Bárbara Civita, Buenos Aires, 4/10/2007.

14 Testimonio de Adriana Civita, Londres, 16/10/2008.

15 El equipo de redacción del tebeo contaba con dos dibujantes Luis Destuet y Salvador Schifer y una secretaria editorial y dibujante Susana (Susi) Hochstimm.

16 Sobre el antifascismo italiano véase Fanesi, 1991 y 1994. 
afianzamiento de un Estado judío en Palestina ${ }^{17}$. En cuanto a la política argentina él se involucró indirectamente, apoyando a los opositores del régimen militar (ofreciendo puestos de trabajo).

La actividad política antifascista lo puso en contacto con otros intelectuales que pronto entraron a formar parte de la editorial (desde Gino Germani a Boris Spivacow, Manuel Sadovski, Oscar Varsavsky ${ }^{18}$, Oscar Cornblit). Tras el golpe de 1943 y en los años del régimen peronista este grupo de amigos y colaboradores constituyó una red informal de oposición, que se encontraba en «reuniones, círculos privados», en las casas de Mario Segre, Leone Amati, Cesare Civita para discutir de política y cultura. Eran reuniones ilegales, muchos de los participantes compartían una ideología «bastante radicalizada y antiimperialista» ${ }^{19}$.

Abril se caracterizó, por lo tanto, desde sus orígenes como una empresa particular en el panorama editorial argentino. Es un lugar donde se encuentran y trabajan intelectuales marginados por sus ideas políticas antifascistas y antiperonistas, socialistas y comunistas y al mismo tiempo es una empresa exitosa en el ámbito de la cultura popular de masa. Ambas vocaciones (y tal vez haya un nexo entre las dos) ${ }^{20}$ se mantendrán en el tiempo y la expondrán en el contexto de la débil democracia argentina de posguerra a críticas y ataques que culminarán, tras el regreso de Perón y el golpe de 1976, en que Civita decidiera forzosamente vender la sociedad y salir hacia un segundo exilio.

\section{LA POSGUERRA Y EL PERONISMO, 1945-1955}

La industria editorial argentina conoce su take off a partir de $1936^{21}$. La Guerra Civil en España interrumpe la tradicional exportación de libros a Sudamérica, abriendo de tal manera espacio para un proceso de «sustitución de importaciones». Al mismo tiempo muchos intelectuales republicanos exiliados en Buenos Aires fundan editoriales. Nacen importantes editoriales como Emecé, Sudamericana y Losada.

17 Civita, 1987. También en el vecino Uruguay varios judíos italianos (como Lea Sestieri) participaron en campañas de difusión y apoyo a la causa sionista. Aldrighi, 1997. Agradezco a Clara Aldrighi por permitirme consultar este documento.

18 Quien dirigirá (1948) Más allá, el primer ejemplo argentino de revista de ciencia ficción.

19 Germani, 2004: 123-126.

20 El hecho de que los mayores editores italianos de revistas (Arnoldi Mondadori, Angelo Rizzoli y Cino del Duca) decidieran hacer ediciones populares pudo deberse a su común «origen socialista». Ferretti, 2007: 92.

21 De Sagastizabal, 1995: 75. 
Es en esta favorable coyuntura (que continúa con la Guerra Mundial) que se constituye Abril, otro producto de la iniciativa de exiliados. Su desarrollo, tras el éxito económico inicial de El Pato Donald (en 1948 la tirada alcanzaba los 300.000 ejemplares), que permite a la empresa hacer nuevas inversiones, se debe al crecimiento del mercado de las historietas al final del conflicto mundial en toda Sudamérica.

La cultura de masa estadounidense se expande al Sur y otros personajes de papel, además de los de Disney, desde Superman a Popeye llegan a ser los protagonistas de las lecturas de los chicos.

México y Argentina son los países donde más se desarrolla la edición especializada en transposiciones al español de las aventuras de nuevos y viejos héroes.

La Argentina peronista no ve con simpatía la penetración de la cultura yanqui y una editorial como Abril puede explotar una experiencia adquirida en Italia en la última fase del régimen fascista.

La idea de Civita y sus socios, en efecto, es la de importar en Argentina personajes creados en Italia como Misterix, la de adquirir los derechos de las historias y, por último, la de producir en Argentina las mismas aventuras haciendo inmigrar ultramar a los dibujantes. Es así como nacen nuevas revistas de historietas: Salgari (1947), Misterix (1948) Rayo Rojo (1949), Cinemisterio (1950), y van a trabajar para Abril dibujantes y autores como Sergio Tarquinio, Guglielmo Lettieri, Ivo Pavone y los venecianos Hugo Pratt, Alberto Ongaro, Mario Faustinelli. Serán los maestros de los dibujantes argentinos que entran a trabajar en Abril. Nacen nuevos personajes y nuevos códigos narrativos como por ejemplo las historias del Sargento Kirk, escritas por Héctor G. Oesterheld y dibujadas por Hugo Pratt o las de Bull Rockett de Oesterheld y Paul Campani ${ }^{22}$.

De la venta y distribución en el exterior (y también de los intercambios y las compras) se encarga el Sindicato Surameris dirigido por el exiliado italiano Alberto Löwenthal, que tiene en Italia como corresponsal la agencia de las hermanas Finzi de Milán²3.

El mundo de los negocios argentino experimenta en esos años una condición particular bien descripta por un industrial italiano, Agostino Rocca, que acababa de trasladarse a Buenos Aires: rapidez, riesgo, reto son las características principales del ambiente. Se precisa prudencia, argentinos e italianos «... offrono gli affari più disparati dai camion ai fazzoletti di seta...» y sobran

22 Brunoro, 2004a: 10-11.

23 Testimonio de Franca Beer, Buenos Aires, 26/9/2007. 
los listos (los «vivos») ${ }^{24}$. La Argentina de posguerra es un país rico que está emprendiendo un proceso de desarrollo industrial que el nacionalismo peronista quiere ver autónomo y «soberano». Hombres como Rocca y Civita comprenden que hay un espacio temporal — antes de que se asomen los poderosos competidores estadounidenses - para trasladar desde la Italia aún maltrecha por la guerra, hombres, tecnologías e instalaciones, sacando provecho de las experiencias de la autarquía fascista.

Es un contexto prometedor pero insidioso: además de la volatilidad del mundo de los negocios, hay que manejar las relaciones con una nueva burocracia estatal y un poder político autoritario a menudo susceptible ante los empresarios extranjeros, cuya colaboración — no obstante- busca ${ }^{25}$.

Durante la posguerra para Abril vuelve a ser importante la red de relaciones que había permitido su creación. La business community local se diversifica aún más, comparada con los primeros años de la década del cuarenta: tras la guerra llegan más inmigrantes italianos, obreros especializados, técnicos, empresarios que se integran en el tejido económico y social argentino. Pueden ser nuevos partners de confianza.

Antigua y nueva colectividad italiana tienden a superar las anteriores fallas políticas y a reencontrarse en lugares y asociaciones (el Circolo Italiano ${ }^{26} \mathrm{o}$ la Federazione delle Società Italiane - Feditalia ${ }^{27}$ ) que facilitan el intercambio de ideas y colaboraciones. No hay que olvidar la actitud peronista de apertura hacia la comunidad judía (otro punto de referencia para la creación de Abril) ${ }^{28}$. Tanto en cuanto a los contactos con la colectividad italiana como a los que entabló con la colectividad judía, se puede decir que Civita utilizó un «capital étnico», entendido como «multiplicador de la dotación individual de capital humano» ${ }^{29}$.

La continuidad con el pasado está también en la hostilidad del nuevo poder político hacia los intelectuales críticos. Expulsados de las universidades, siguen encontrando en las editoriales una salida profesional y un lugar de asilo.

24 «... ofrecen los negocios más heterogéneos desde camiones hasta pañuelos de seda...».Agostino Rocca es el fundador de la compañía Techint. Lussana, 1999: 115.

25 Véase el caso emblemático de los ataques de Perón a un empresario como Vittorio Valdani, ideológicamente afín al peronismo, pero «extranjero». Scarzanella, 2007: 247.

26 Smolensky, Jarach, 1999: 125.

27 Schneider, 2000.

28 Rein, 2001: 57-100. Entre los nuevos industriales favorecidos por el peronismo se encuentra José Ber Gelbard.

29 Garruccio, 11 (Venezia, 2000): 469. El capital étnico funciona como un multiplicador (spillover étnico). 
El desarrollo de las revistas de historietas (diversificación de las cabeceras y mejoras técnicas en la gráfica y en la «diagramación», aumento del personal, investigaciones de mercado ${ }^{30}$ ) inducen a Abril a trasladarse a una nueva sede más grande.

El know how italiano aprovechable en la Argentina de posguerra, no sólo tenía que ver con los tubos de acero de Agostino Rocca, sino también con los productos editoriales de reciente creación y gran éxito: las fotonovelas. La fotonovela italiana (la primera, Bolerofilm, salió en 1947 en la editorial Mondadori en la que Civita había trabajado) constituye una invención original. Se basa en la anterior experiencia del cine autárquico que había creado divos tan famosos como los de Hollywood y en una estructura productiva y técnica eficaz. La interdependencia entre cine y fotonovela durante la posguerra da origen a un filón popular que se articula en el cine del así llamado «neorrealismo popular» (películas de estilo moderno con clásicas tramas melodramáticas) y en los semanarios como Grand Hotel, Sogno y Bolerofilm ${ }^{31}$.

El viaje de Civita a Europa en 1947 (donde retoma contactos en Italia y Francia con los editores con quienes había trabajado), conduce, tal como había sucedido con las historietas, no sólo a la adquisición de los derechos de los productos europeos, sino también a la creación de un nuevo sector de la empresa que produce fotonovelas con autores, técnicos y actores argentinos. Se produce un nuevo boom de revistas como Idilio (1948) y Nocturno ${ }^{32}$.

El comienzo de esta nueva actividad coincide con la conclusión de un experimento que particularmente uno de los socios de Abril, Paolo Terni, quería llevar adelante: el de la colección de libros para adultos de alto valor cultural. Es la colección Ciencia y Sociedad, dirigida por Gino Germani a partir de 1945. Se trataba de traducciones de obras de vanguardia que iban desde Erich Fromm y su El miedo a la libertad hasta Margaret Mead con Adolescencia y cultura en Samoa.

El experimento de la edición de calidad, sin embargo, no tiene éxito y el sector se cierra ya en $1948^{33}$. Gino Germani encuentra entonces en las fotonovelas otro empleo aún menos creíble que el de director del personal que ya ocupaba. En Idilio se ocupa junto con el sociólogo Enrique Butelman de una

30 Tanto de la gestión del personal, como de las investigaciones de mercado se encarga el sociólogo Gino Germani.

31 Sobre la fotonovela italiana véase Bravo, 2003.

32 Flores, 1977. Scarzanella (en prensa).

33 Véase Spivacow, 1995: 35. Germani, 2004: 116-117. Blanco, 2006: 89-90. La colección fue vendida a Paidós. 
original página de interpretación de los sueños de las lectoras, ilustrada con los curiosos fotomontajes de Grete Stern ${ }^{34}$.

Como la ópera del siglo XIX, la fotonovela italiana acompañó la última oleada inmigratoria italiana a Argentina y fue vehículo de integración. Los divos italianos de las fotonovelas (y luego del cine) desde Gina Lollobrigida hasta Sofia Loren eran rostros familiares para los recién llegados y lo llegaron a ser tras poco tiempo para los argentinos. Amedeo Nazzari emocionaba al público femenino desde la pantalla y desde el papel (rodó en Argentina una película en 1947) y lo apreciaba la primera dama y ex actriz Evita Perón.

La triangulación USA/Italia/Argentina ya experimentada con las historietas (importación de modelos estadounidenses en Italia, su «italianización» y por último, su exportación a Argentina) se repite con la fotonovela que adapta los modelos de Hollywood al gusto «latino» y combina el melodrama con las técnicas del montaje cinematográfico.

El tema de los guiones es «el amor frustrado». Los sentimientos son «fuertes», los personajes viven una continua lucha contra las adversidades y conducen al lector a través de una trama apasionante y rica de golpes de escena y secretos desvelados. El éxito de Idilio es increíble, en poco tiempo se convierte en la segunda revista más vendida en el país, con más de 250.000 copias semanales.

Muy importante es el diálogo con las lectoras: el «pequeño correo» desempeña un papel pedagógico (que mantendrá en las sucesivas revistas femeninas de Abril). Lo edita Marisa Rossi, de familia italiana que responde así a la clásica pregunta si conceder o no «la prueba de amor» al novio: «el amor no necesita pruebas ${ }^{35}$. La revista registra el rápido cambio de las costumbres y brinda una guía a la nueva vida urbana, sugiriendo comportamientos, estilos de vida y consumos.

Civita decide ampliar su radio de acción fuera del territorio argentino. En primer lugar en Brasil, donde desde 1947 existía una sociedad, la Editora Abril Ltda., dirigida por un ciudadano brasileño, por respeto a la ley, y creada por cuatro socios amigos de Civita ${ }^{36}$. En Río de Janeiro y São Paulo, desde su primer

34 Plotkin, 1999: 621-624. Vezzetti, vol. 3, 1999: 186-192.

35 Testimonio de Marisa Rossi, Buenos Aires, 3/10/2007.

36 Según los documentos de la Junta Comercial do Estado de Sao Paulo la sociedad fue registrada el 16 de diciembre de 1947 como Editora Abril Ltda. con los siguientes socios: Enrico Frisoni, Piero Kern, Marcello Frisoni y Enrico Rimini. Se trataba de ciudadanos italianos, lo cual estaba prohibido por la Constitución de 1946, que no permitía que extranjeros fuesen propietarios de empresas periodísticas. Sin embargo, esto fue ignorado en el momento de la registración. Cfr. Dantas Taveira Cabral, 2006: 7. 
viaje por Sudamérica, Civita había entablado contactos y en los años que siguieron se había ido creando una red de amistades que comprendía a empresarios italianos y brasileños, exiliados italianos ${ }^{37}$. Desde 1945 Abril estaba explorando la posibilidad de abrir una tipografía en São Paulo. Sobre todo Civita era quien, entre los otros socios, más ponía la mira en un desarrollo en el país vecino temiendo que el peronismo pudiese convertirse en un régimen autoritario. Además, el mercado brasileño se presentaba particularmente prometedor. Como Civita escribe a Arnoldo Mondadori en noviembre de 1949 (proponiendo una colaboración), en Brasil escaseaban las buenas publicaciones y las editoriales de calidad. El empeño del editor italiano debía darse en dos tiempos: en un primer momento se iniciaría la actividad editorial y en un segundo momento la industrial, importando desde Italia las máquinas tipográficas ${ }^{38}$.

La actividad editorial debía empezar por las historietas argentinas y las de Disney. Como gerente de la sociedad Cesare Civita había pensado en su hermano Vittorio que se había quedado en los Estados Unidos, trabajando en el sector editorial ${ }^{39}$. Ya existía entre Abril y Mondadori una intensa colaboración en el campo de la historieta y de la fotonovela con intercambios de productos y el editor italiano parecía interesado en la «combinación Brasil» ${ }^{40}$. Al final Arnoldo Mondadori prefirió no participar en el proyecto que de todas formas se puso en marcha con dos tebeos Raio Vermelho y $O$ Pato Donald, que salieron en la primavera-verano de 1950. En 1952 apareció también la versión brasileña de Nocturno con el título de Capricho.

Vittorio Civita en vano intentó obtener para la Editora Abril Limitada ${ }^{41}$ el apoyo financiero de Nelson A. Rockefeller o de la Economic Basic Economy Corporation (EBEC) $)^{42}$. Luego hará entrar en la sociedad a Gordiano Rossi, un empresario minero hijo de italianos y el grupo Smith de Vasconcelos ${ }^{43}$.

37 Entre éstos el abogado Enrico Rimini y Marcello Frisoni (quien lo puso en contacto con el empresario italiano Matarazzo).

38 Carta de Cesare Civita a Arnoldo Mondadori, 23 de novembre de 1949, Archivio Storico Arnoldo Mondadori, Milano (AME), Fondo Arnoldo Mondadori Editore, legajo Civita Cesare.

39 La biografía oficial de Vittorio Civita en http://www.centenariovictorcivita.com.br/ sostiene que en los Usa había sido empresario de la industria grafica.

40 A través de la agencia Finzi.

41 En la que era socio de mayoría el hermano Cesare.

42 Carta de Fred Gardner a FILES, 1 de diciembre de 1950, Rockefeller Foundation Archives, New York (RAC), Record Group 4 Nelson A. Rockefeller, series E-Personal, countries, caja 11, legajo 75-Brasil, Cr-Cu, 1945-1971. EBEC fue fundada por Nelson A. Rockefeller en 1947 para financiar el desarrollo industrial de los países latinoamericanos.

43 Cfr. Dantas Taveira Cabral, 2006: 8. 
Todo esto confirma la capacidad de los Civita para moverse en una compleja red internacional, tanto política como económica.

Además de la expansión hacia Brasil y los contactos con Italia, Abril también potencia al principio de los años cincuenta su actividad de distribución absorbiendo al revendedor argentino y creando una propia sociedad, RYELA (Revista y Ediciones Latino Americanas).

Los resultados obtenidos con las fotonovelas de producción nacional hacen nacer la idea de desarrollar un ambicioso proyecto (que no se realizará) para producir conjuntamente entre Italia y Argentina fotonovelas con artistas italianos de fama mundial (Gina Lollobrigida, Vittorio De Sica) para conseguir «tirature mirabolanti» y ventas en varios países de Europa y América ${ }^{44}$.

El éxito de las fotonovelas es paralelo al desarrollo de las publicaciones para la infancia que se diversifican y llegan a ser producciones originales.

Terni, Civita e Spivacow crean decenas de colecciones, dos de las cuales obtienen mucho éxito: Gatito y Bolsillitos. Son libros de pequeño tamaño que se venden en los quioscos. Brindan a los lectores nuevas historias cada semana, con personajes alegres, tramas originales y modernas.

En estas colecciones trabajan escritores y dibujantes reclutados en el ámbito de la red amistosa, política, económica establecida desde hacía tiempo y que ahora incluye también las nuevas generaciones. Hijas de amigos eran por ejemplo: Eleonora María Smolensky, Franca Beer, Malvina Segre, Paola Ravenna: la primera entra a trabajar en el sector de libros para niños, escribiendo y dibujando para la colección Gatito, la segunda trabaja en los tebeos y luego inaugura la página publicitaria de la revista Claudia, la tercera es la secretaria de Germani, la cuarta, tras pasar por varios cargos, llegará a ser la vicedirectora de Claudia.

La idea de pasar de las revistas a los libros para niños fue impuesta también por el hecho de que «había prohibición de hacer nuevas revistas en Argentina por la escasez de papel $\gg^{45}$.

La expansión de la editorial se mueve en un contexto de progresivo recrudecimiento del régimen peronista paralelo a la conclusión de la fase expansiva de la economía. Es a principios de los años cincuenta que se crea un monopolio de la información a través de la adquisición o la expropiación (véase el caso de La Prensa) de los periódicos opositores, el control de las importaciones de papel, el rol intimidatorio de los sindicatos dentro de las empresas. To-

44 Carta de Cesare Civita a Arnoldo Mondadori, 3 de agosto de 1954, AME, Fondo Arnoldo Mondadori Editore, cit.

45 Spivacow, 1995: 31. Bolsillitos vendía hasta 110.000 ejemplares por semana. Se publicaron miles de títulos. 
dos estos problemas los experimenta también una editorial como Abril, aunque sus publicaciones no toquen el ámbito del debate político y cultural. Sin embargo, los problemas existen e inducen a Civita a asumir un rol público, a desempeñarse como presidente del sindicato de los empresarios del sector, La Asociación Argentina de Editores de Revistas ${ }^{46}$.

\section{LOS AÑOS SESENTA: LA INTERNACIONALIZACIÓN}

Tras la caída de Perón la editorial da otro paso adelante y lanza una nueva revista femenina, Claudia, en mayo de 1957 (el modelo es el norteamericano Ladies' Home Journal).

Desde el comienzo de los años cincuenta, Cesare Civita deseaba publicar una revista de actualidad al estilo de la italiana Epoca de Mondadori, pero juzgaba que aún no había llegado el momento ${ }^{47}$. Recién en 1962 saldrá Panora$m a$, gracias a un acuerdo con el grupo Time-Life y Mondadori.

La década de los sesenta es la de mayor dinamismo para la empresa, no sólo porque salen productos innovadores como Claudia y Panorama, y por la consiguiente mayor internacionalización gracias a licencias de editores estadounidenses y europeos, sino también por el inicio de un proceso de integración vertical con la creación de una planta gráfica $(1963)^{48}$.

Si en el momento de la importación de las maquinarias para la tipografía de Abril brasileña Civita se había dirigido finalmente a la industria estadounidense, cuando se trató de instalar una nueva y moderna planta cerca de Buenos Aires, envió a su hijo Carlo a Europa y se valió de maquinarias y técnicos de Italia y Suiza.

La Fabril Financiera, que hasta ese momento había impreso las revistas de Abril, al poco tiempo entra como socia en la editorial ${ }^{49}$. Esto atestigua que la

46 En 1948 un grupo de 19 editores, entre los cuales se encontraban Julio Korn, Emilio Ramírez, César Civita, Guillermo Castromán, Jacobo Muchnik, Dante Quinterno, Constancio Vigil, Ramón y Claudio Columba, Guillermo Divito y Jaime Botana, crearon la Asociación Argentina de Editores de Revistas (AAER). http://www.learevistas.com/editoresrevistas/inst historia.asp.

47 Carta de Cesare Civita a Alberto Mondadori, 20 de mayo de 1953, Archivio Storico Arnoldo Mondadori, Milano (AME), Fondo Il Saggiatore, sección carteo 1934-1976, legajo Civita Cesare.

48 Con el Gobierno de Lonardi se eliminó el IAPI (que controlaba las importaciones de papel).

49 Civita volvió a comprar luego las cuotas de la Fabril en 1965, gracias a la venta de una participación en la Mexabril a Pagliai. Civita, 1987: 262. 
red de la business community desempeñaba funciones complejas y no sólo meramente económicas y técnicas. La Fabril - como se dijo - era, en efecto, un grupo poderoso que mantenía muy estrechas relaciones con el poder político y militar. Si Civita juzgaba poco beneficiosa la colaboración con el grupo en el plano técnico, por otro lado la consideraba importante en el plano político, porque servía: «per coprirci le spalle da eventuali rappresaglie del governo» ${ }^{50}$.

Hay que tener en cuenta también el hecho de que el carácter internacional de la sociedad no le agradaba al nacionalismo militar. Cesare Civita y Vittorio Civita tuvieron que renunciar a la ciudadanía italiana, Abril brasileña debió demostrar ser una empresa «típicamente» brasileña ante la Comisião de Inquerito creada en 1966 para investigar los medios ${ }^{51}$, y en 1970 Cesare Civita debió rescatar las participaciones extranjeras en la editorial.

La Editorial Abril consigue mantenerse al paso de las transformaciones sociales, políticas y culturales del país. Al desarrollo de la industria automovilística corresponde efectivamente el lanzamiento de la revista mensual Parabrisas (1960) y al de la moda autóctona, la salida de Claudia. La apertura política de los años del presidente Illia (julio 1963-junio 1966) permite por último que aparezcan semanarios de actualidad como Panorama y Siete Días Ilustrados $(1964)^{52}$ y una publicación como Adán, imitación soft de la estadounidense Playboy, de breve vida porque sale en vísperas del golpe de Onganía.

Con Claudia, la editorial Abril desafía a las viejas editoriales como Atlántida y Korn y sus productos obsoletos, Para Ti y Vosotras, que alimentaban el tradicional modelo femenino basado en el énfasis del rol doméstico. Explotando el crecimiento numérico y cultural de la clase media y la apertura del mercado de trabajo a las mujeres, Claudia propone un nuevo modelo de mujer «liberada» que se nutre de ejemplos europeos y estadounidenses ${ }^{53}$. Claudia era una revista femenina de vanguardia incluso desde el punto de vista gráfico. Era un producto elegante por sus contenidos y por la estética de las tapas (dibujadas inicialmente por Raúl Alonso) y por los servicios en colores. Esto aseguraba un aumento en la publicidad (más del 30\% de las páginas), aumento de ventas (130.000 ejemplares como promedio) y lo convertía en un producto que

50 «... para guardarnos las espaldas ante eventuales represalias del Gobierno», Civita, 1987: 262.

51 Las acusaciones se referían tanto al rol de Cesare Civita como al del Grupo Time-Life en la editorial. Dantas Taveira Cabral, 2006: 11.

52 A quien se unió en 1972 el seminario quincenal Siete Días Internacional que debía brindar «la imagen exacta del presente continental».

53 Cosse, en prensa. Feijoo y NARI, 23/1 (Thousand Oaks, CA, 1996). Las viejas revistas se vieron obligadas a hacer filtrar en sus páginas los síntomas del cambio, señalando la importancia del trabajo femenino extradoméstico. 
podía exhibirse también en manos de estudiantes y profesionales, sin el estigma de la «prensa rosa» ${ }^{54}$.

Abril sabe manejar la inicial competencia de la televisión. Inaugurada en 1951, recién en 1960 contará con tres canales ${ }^{55}$. En los Estados Unidos y en Europa constituía una competencia insidiosa para la prensa femenina, tanto por los temas tratados como por la recogida de publicidad. En Argentina el costo de los televisores aún no hacía de la televisión un producto de consumo de masa (dos millones y medio de aparatos en 1968). De todas formas, la revista Claudia no duda en utilizar el medio televisivo con un programa suyo de consejos y moda. Abril lanza en 1963 TV Guía.

Con la apertura de una boutique en Buenos Aires se ponen a disposición de los consumidores los productos para el hogar de «estilo Claudia», propagandados en las páginas de la revista. Respondiendo al pedido de sus lectores, Claudia señala los espectáculos y las actividades culturales más importantes de la ciudad $^{56}$.

Panorama, tal como las revistas contemporáneas Primera Plana y Confirmado, se dirige a un público deseoso de adecuarse a los consumos y los valores de las sociedades occidentales más avanzadas. Escribe Isabella Cosse: «En 1960, los sectores medios constituían el 43\% de la población, habían mejorado su estándar de vida mediante el acceso a la educación media, la adquisición en propiedad de su vivienda y el consumo de bienes y servicios, como los electrodomésticos y las vacaciones pagadas ${ }^{57}$.

Panorama, como su homólogo italiano de Mondadori, es una revista de tipo nuevo, que no apuesta ya sólo a los servicios fotográficos (dado que a ese punto la televisión ya responde de manera más eficaz que la prensa al pedido de un «periodismo por imágenes» ${ }^{58}$ ), sino que privilegia el texto escrito, adoptando un estilo sobrio, llevando a cabo investigaciones, brindando noticias «incómodas». Recuerda el periodista Mario Eduardo Ceretti: «Panorama tenía una forma de investigar profunda, con un estilo elegante, ameno, gracioso y a veces pedante, como también era Time» ${ }^{59}$. La presentación gráfica, como en el caso de Siete Días, mejora gracias a la importación de maquinarias italianas. Con el intento por mantener «los hechos separados de las opiniones» como ha-

54 Testimonio de Héctor Zimmerman, Buenos Aires, 25/9/2007.

55 Aguilar, 1999: 256.

56 Las revistas como Idilio y Nocturno entretanto siguieron teniendo éxito de venta. Estaban destinadas a un público femenino menos rico y menos culto.

57 Cosse, 17/1 (Tel Aviv, 2006): 41.

58 Ajello, 1976, vol. 3: 206.

59 Ulanowski, 2005: 226. 
bía propuesto Times antes que nadie, se aspira a «hacer una revista que merezca el respeto de todos los sectores dirigentes del país. $\rangle^{60}$

Claudia y Panorama («La revista de nuestro tiempo») son termómetros de la fiebre modernizadora argentina. Se imitan revistas extranjeras (Marie Claire o Time-Life) como antes se habían imitado los tebeos, los libros para niños y las fotonovelas argentinizando los modelos originales. En este período aumenta el impulso a crear un producto que no sea local, sino que pueda atraer a lectores de otros países latinoamericanos. No sólo — como en el pasado - las nuevas publicaciones de Abril constituirán un modelo para revistas destinadas al público de lengua portuguesa de Abril brasileña, sino que Claudia y Panorama conquistarán los mercados de países vecinos (Uruguay, Chile, Colombia, Perú, Centroamérica) y se creará una sociedad mixta en México, la Mexabril, asociada con el poderoso empresario mexicano de los medios Rómulo O'Farril ${ }^{61}$.

Una vez más la red transnacional se revela eficaz. Nuevos socios mexicanos se identifican gracias a una italian connection. Es el empresario Bruno Pagliai, socio de Agostino Rocca en México en el sector de los tubos de acero (TAMSA) y propietario de la Novaro (uno de los líderes en el sector de los tebeos) quien se asocia a Civita ${ }^{62}$.

La característica familiar de la Abril se ve confirmada también en esta ocasión. La inversión en el exterior se había manejado en Brasil a través de un miembro de la familia, porque Cesare Civita consideraba «indispensabile un uomo di assoluta fiducia, capacità, abilità» ${ }^{63}$ y había escogido por eso a su hermano. Para dirigir la nueva sociedad mexicana fue enviado el yerno de Civita, Giorgio de'Angeli.

Abril era, pues, al mismo tiempo una editorial con vínculos internacionales y una empresa familiar fuertemente caracterizada por el papel del fundador, un típico «editor protagonista» como en Italia lo eran Mondadori o Rizzoli.

En efecto, los primeros socios en algunos casos vendieron sus cuotas (Terni e Amati), decidiendo volver a Italia, otros (Levi) redujeron su participación. Quedó Diena ${ }^{64}$, pero dejaba que de la gestión se ocupara sobre todo Cesare Civita, dado que él tenía sus mayores intereses en Uruguay en el sector de la producción de papel (sociedad PAMER).

\footnotetext{
60 Editorial Abril, 1973c. Agradezco a Carlo Civita la consultación del opúsculo.

61 Abril controlaba también la agencia publicitaria Surameris Propaganda.

62 Pagliai y O'Farrill formaban parte de un influyente grupo de empresarios vinculados al poder político.

63 «... indispensable un hombre de absoluta confianza, capacidad, habilidad», AME, Fondo Arnoldo Mondadori cit., carta cit.

64 Socio también de Abril brasileña desde 1957 hasta fines de los años sesenta.
} 
Civita había delegado a su hermano y al yerno la expansión en el extranjero; al hijo, el proceso de integración (producción gráfica), mientras a la mujer y a la hija mayor había confiado el trabajo periodístico y la dirección de revistas. La mujer Mina, dirigía Claudia, la hija Adriana era periodista ${ }^{65}$, directora de un semanario de breve vida, Semana Gráfica (1969), y se ocupaba de las relaciones públicas, que tenían su centro convivial en el roof garden del Edificio Abril, la nueva y moderna sede de la editorial inaugurada en 1967.

Si bien las mujeres habían comenzado a entrar en el periodismo, los roles de director y enviado seguían siendo tradicionalmente masculinos y a menudo los artículos de las periodistas sólo llevaban su sigla ${ }^{66}$. Abril constituyó una excepción. Mina dirigió Claudia imprimiendo no sólo un nuevo estilo en el sector de los servicios de moda, sino transformando además las revistas en escaparates de escritores europeos, norte y sudamericanos (desde Moravia a Cortázar), invitados a colaborar con sus cuentos. Adriana Civita, siguiendo el ejemplo de una de las firmas más famosas de las revistas de Abril, la de la italiana Oriana Fallaci, se especializó en entrevistas a personajes famosos, debates e investigaciones y fue corresponsal desde el Vietnam en guerra.

La característica familiar de Abril no era en absoluto excepcional. Para todas las editoriales la propiedad (total o mayoritaria), la gestión y la definición de las estrategias concentradas en las manos de miembros de la misma familia responde a una exigencia de «continuidad en la conducción, transmisión de conocimientos en forma vivencial, coherencia entre los valores y criterios comerciales y culturales» ${ }^{67}$. Recién a principios de los años setenta Carlo Civita comenzó a valerse de gerentes formados en las modernas técnicas de gestión ${ }^{68}$.

El sello familiar de la empresa llevaba además a que se buscara una relación paternalista con el personal. Los empleados de la editorial habían aumentado con el tiempo, pasando de un pequeño grupo donde todos se conocían hasta llegar a los mil trescientos (entre periodistas, obreros, técnicos, fotógrafos, publicitarios, administrativos, etc.).

Con todo, Cesare Civita había intentado mantener un clima particular en la empresa ofreciendo además de altos sueldos, también otros benefits que vinculaban a los empleados, como bonos de compra en tiendas, bonos para acceder a servicios, becas para los hijos. Cuando era necesario contratar a un nuevo empleado, según la costumbre inicial, se buscaba al candidato entre los fami-

65 Para Claudia, Siete Días, Panorama.

66 Ulanovski, 2005: 188-189.

67 De Sagastizábal, 1995: 95.

68 Testimonio de Eduardo Guibourg, Buenos Aires, 28/9/2007. 
liares de los viejos empleados ${ }^{69}$. En las negociaciones con los sindicatos, aun en los momentos difíciles, Civita se había esforzado por instaurar una relación personal con los dirigentes, tal vez subrayando el común origen italiano. Abril podía contar con su propio éxito y prestigio para favorecer las relaciones con los empleados: trabajar para las revistas de la editorial de hecho era una señal de distinción en los años sesenta. Como recuerda Eduardo Guibourg: «para un periodista decir yo trabajo en la Editorial Abril era como decir ahora yo trabajo para el New York Times» ${ }^{70}$.

El ambiente de trabajo había mantenido las mismas características iniciales de informalidad y organización nada rígida. Cesare Civita, apasionado del cine, rodó un documental con un empleado de Abril como protagonista (personificado por Alberto Ongaro) que decide no ir a trabajar y pasar el día vagando por la ciudad ${ }^{71}$.

\section{LOS AÑOS SETENTA. LA INTEGRACIÓN VERTICAL}

Cesare Civita había dado origen a Abril en 1941 pudiendo contar con un «capital de clase» constituido por medios financieros, know how, experiencias, habilidades, vocación al riesgo. Había recurrido luego al «capital social» representado por las relaciones familiares, amistosas, étnicas, profesionales. Estas relaciones de confianza habían ampliado sus capacidades de acción y fomentado el desarrollo de sus actividades ${ }^{72}$.

Pero Abril, para crecer, para pasar de ser una empresa sustancialmente familiar a gran empresa internacionalizada e integrada verticalmente, no sólo necesitaba aumentar su capital físico y social, sino también poder contar con favorables condiciones de mercado y con un respaldo por parte del Estado.

Desde sus comienzos, la editorial se había beneficiado de un mercado local en expansión: había sabido responder al aumento de la demanda de productos como los tebeos, las fotonovelas, las revistas femeninas, los semanarios de actualidad. Aprovechando el desfasaje temporal entre el desarrollo de un determinado producto en Europa y en los Estados Unidos y su difusión en Argentina, se había garantizado la ventaja de saber «importar» y adaptar al gusto local

69 Testimonio de las periodistas Haydeé Codda y Julia Pomier, Buenos Aires, 20/10/2007.

70 Testimonio de Eduardo Guibourg, cit.

71 Testimonio de Franca Beer, cit. Cesare Civita había realizado en Italia dos películas con Mario Monicelli y Alberto Mondadori: Il cuore rivelatore de 1934 y I ragazzi della via Paal de 1935.

72 Sobre el concepto de capital social véase Mutti, 1998: 11-35. 
las novedades. Civita había sabido comprender el gusto del público y por esto había llegado a ser un editor exitoso.

La coyuntura económica había sido relativamente favorable, aunque Argentina, a diferencia de otros países latinoamericanos, había conocido varios saltos coyunturales durante los que se conocen como los «treinta gloriosos» años del desarrollo de posguerra. Hemos visto que en los años sesenta Abril completó la apertura hacia el mercado latinoamericano. También forman parte de esta expansión y de esta vocación continental la producción de fascículos para enciclopedias. Entre éstos, son emblemáticos los que se encargan al historiador José Luis Romero para una historia latinoamericana, que supera el límite tradicional de las historias nacionales.

Un opúsculo publicado por Abril alrededor de 1973 atestigua los resultados obtenidos por la editorial ${ }^{73}$. También testimonia de la puesta en marcha de un proyecto ambicioso, el de sumar al taller gráfico (que tenía 750 empleados) una gran fábrica que produjera papel para periódicos, controlando de esta manera la totalidad del ciclo productivo.

Este proyecto había surgido después del golpe de Onganía. Los años entre 1969 y 1972 se caracterizan por el lanzamiento de importantes iniciativas en ámbito industrial. Escribe Jorge Schvarzer: «En aquel período, y pese a los constantes cambios en el poder político que registraba la coyuntura, se abrió paso una estrategia dirigida a impulsar diversos grandes proyectos industriales en sectores básicos con el objeto de "integrar" hacia atrás la estructura productiva nacional». Se trataba de proyectos de dimensiones tales como para exigir «una meticulosa promoción estatal» ${ }^{74}$. Respondían al modelo ISI (industrialización sustitutiva de importaciones), se iniciaron en 1969, se incorporaron al Plan Trienal de 1973 y fueron llevados adelante hasta el golpe de 1976. Uno de estos proyectos ambiciosos era justamente el de una fábrica destinada a producir papel para la prensa. Alrededor de esto se desató un conflicto de intereses que comprendía importadores y consumidores de papel, conflicto acentuado por el hecho de que en esos años se alternaron en el poder siete presidentes diferentes y un número aún mayor de ministros y funcionarios del $\mathrm{Mi}$ nisterio de Economía.

73 El opúsculo indica las nuevas publicaciones como BienEstar, Corsa, Contigo, Idiliofilm, Supernovelas, Crucigrama, Asterix, Lucky Luke, y las entregas de obras enciclopédicas como Argentina, Gran Historia Latinoamericana, Libro de la vida editadas por Abril Educativa y Cultural (también producía audiovisuales).

74 Schvarzer, 38/131 (Buenos Aires, 1993): 379. «... el Estado terminó estableciendo los contornos de cada proyecto, desde la definición misma de los objetivos buscados hasta los aspectos técnicos, que debía tener cada planta, sus requisitos económicos y financieros e, incluso, su misma ubicación geográfica». 
Abril jugó sus cartas en este conflicto. La idea de crear una papelera había surgido después de que Onganía diera lugar en 1969 al Fondo para el Desarrollo de la Producción de Papel y Celulosa (decreto-ley 18.312 de agosto de $1969)^{75}$.

El proceso de creación de una sociedad (PROIMPA) con socios de minoría (César Doretti y Luis Alberto Rey), para estudiar el proceso técnico y de investigación de las maquinarias finlandesas a importar, culminó tres años más tarde cuando el Gobierno de Alejandro Lanusse dio la autorización para poner en marcha la fábrica de Papel Prensa ${ }^{76}$. Pero ya en diciembre de 1973 Civita (después de la elección de Perón) tuvo que vender su cuota a Rey (que luego la cedió al banquero Graiver) a causa de fuertes presiones políticas ${ }^{77}$.

El opúsculo de Abril había proclamado con excesivo optimismo «Papel Prensa es una obra que testifica la capacidad del empresariado nacional y asegura uno de los postulados de la real libertad de prensa: la independencia del papel extranjero».

El control de la distribución del papel para periódicos era uno de los principales instrumentos de que disponía el poder político para limitar la libertad de prensa, junto a la censura (o la incitación a la autocensura) y al crédito de los bancos estatales ${ }^{78}$.

Tanto cuando manejaba las importaciones (como había hecho Perón con el Instituto Argentino Para Intercambio- IAPI) como cuando participaba en la producción nacional, el Gobierno tenía en sus manos un poderoso medio de control.

Civita era un empresario ambicioso, pero esta vez había intereses demasiado poderosos en juego.

\section{El SEGUNDO EXILIO}

Perón no había olvidado el antiperonismo de Abril. Tras su muerte, Isabel Perón y López Rega tenían un motivo más para ser hostiles hacia Civita. Los intelectuales a los que como siempre ofrecía asilo eran diferentes a los de la

75 Onganía fijó una tasa de contribución del 10\% a la importación de papel hasta que la papelera argentina se pusiera en marcha. Ramos, 1993: 166.

76 Sobre los detalles de la operación véase Ramos, 1993: 167-170.

77 Luego los militares acusaron a Graiver de estar vinculado a los montoneros y confiscaron sus bienes. Las acciones de Papel Prensa terminaron en manos de las principales sociedades editoras de periódicos (La Nación, Clarín y La Razón). Sobre Graiver véase Gasparini, 1993: 171-182. El ministro Gelbard apoyó a Graiver en la operación.

78 Onganía invitaba a la prensa a «ser responsable». De Riz: 53. 
posguerra. Como todos los intelectuales, de 1969 en adelante, eran más radicalizados y estaban inmersos en un clima de violencia y de expectativas de la revolución inminente que aproximaba paradójicamente a izquierda (peronista y no peronista) y militares. Muchos de los empleados de Abril eran simpatizantes de las «formaciones especiales» y de la Juventud Peronista. Para el peronismo «ortodoxo» representaban una oposición mucho más hostil que la tradicional que siempre había existido en la editorial.

Isabel Perón no apreció la buena voluntad de la revista Claudia que en 1974 la eligió «mujer del año». Isabel seguramente era un modelo bastante distante del que proponía la revista en los años sesenta, encarnado - por ejemplo - en la juventud y el anticonformismo de Geraldine Chaplin. La presidenta comentó de la siguiente manera la salida del artículo en su honor: «como decía Perón: el lobo se disfraza de cordero» ${ }^{79}$.

Al publicarse en la tipografía de la editorial el semanario de la organización El Descamisado, la tensión aumentó ${ }^{80}$.

Se rompió también el clima paternalista, los benefits y la sociabilidad empresarial fomentada por los Civita (encuentros en el roof Abril, regalos navideños) fueron interpretados negativamente y rechazados por muchos. Los conflictos se agudizaron ${ }^{81}$.

Civita se encontró «acorralado» entre el periodismo «militante» y las amenazas de la Triple A. Recibió una advertencia en 1974, cuando estalló una bomba frente al Edificio Abril y su nombre apareció en una lista de intelectuales amenazados de muerte por la organización de López Rega.

Civita se trasladó por consiguiente a Brasil y después a Uruguay, donde con muchas dificultades intentó dirigir la empresa desde el exterior junto a su hijo Carlo. Intentó fortalecer Abril con un aumento de capital. También en estos momentos dramáticos le ayudaron los antiguos vínculos étnicos y amistosos: fue uno de los socios, Manuel Diena, quien participó en este intento por defender la empresa.

Tras el golpe de 1976, como muchos, Civita pensó que las cosas podían cambiar. Pero 1976 no fue una reedición de 1966, los militares habían decidido «hacerse cargo de una sociedad enferma e imponerle su disciplina militar» ${ }^{82}$.

79 Testimonio de Héctor Zimmerman, cit.

80 Testimonio de Ernesto Schoo, Buenos Aires, 3/10/1907 y de Eduardo Guibourg, cit.

81 Hubo violentas «acciones de propaganda» en los locales de la editorial. Testimonio del periodista Mario Ceretti, 17/11/2008. Cesare Civita atribuye a la Triple A una de estas acciones aparentemente reivindicadas por Montoneros.

82 De Riz, 2000: 188. 
Abril no podía retomar su camino ilusionándose de «che il peggio fosse passato». Los militares no querían dejar el control de un sector tan sensible para la formación de la opinión pública en manos de editores «di origine straniera, e per giunta ebrei» ${ }^{83}$.

En 1976 una nueva y aún más grave amenaza acechó a Civita: su apartamento fue ametrallado y llegaron nuevas advertencias para que se marchara. Desde Uruguay, donde se había refugiado, comenzó a organizar la venta de la editorial.

El origen de Abril y su primer desarrollo habían estado vinculados, como habíamos visto, a las relaciones entre Civita y Mondadori. La colaboración había continuado y el interés de Civita por desarrollar iniciativas conjuntas siguió en el tiempo, como testimonian las cartas a Alberto Mondadori sobre la posible publicación de varias enciclopedias (de los jóvenes, deportiva) o colecciones de libros baratos ${ }^{84}$.

La venta de la Abril está relacionada con otra italian connection. Entra en juego la editorial tradicionalmente rival de Mondadori, Rizzoli. Ya desde 1968 Civita había colaborado en el ámbito de los coleccionables con la editorial de Milán a través de la sociedad ANESA.

La editorial Rizzoli, en situación difícil desde 1975, se había encomendado a dos miembros de la masonería, Licio Gelli y Umberto Ortolani, ambos con intereses económicos y relaciones políticas importantes en Argentina ${ }^{85}$. Angelo Rizzoli con la financiación del banco de Ortolani, el Basifud (cuatro millones de dólares), inicia la operación de compra de los Civita en 197786, dando origen a una sociedad (CREA- Celulosa Rizzoli Empresas Asociadas) con la Celulosa Argentina (que tiene el 51\%), cercana al Gobierno y propietaria de la editorial Korn ${ }^{87}$.

En este momento Abril tiene 22 publicaciones con una venta de dos millones de ejemplares, 1.400 empleados y una facturación de alrededor de $50 \mathrm{mi}$ llones de dólares.

83 «que lo peor había pasado»; «de origen extranjero, y además, judíos», Civita, 1987: $280,281$.

84 Cartas de Cesare Civita a Alberto Mondadori, 25 de novembre de 1953, 22 de marzo de 1967, AME, Sezione Il Saggiatore, cit.

85 Gelli era amigo de Perón, y había constituido una logia secreta, la P2, a la que se adhería en Argentina también López Rega. La logia fue sometida en Italia a una investigación parlamentaria. Gelli fue condenado en 1994 por la bancarrota de un instituto financiero, el Banco Ambrosiano.

${ }^{86}$ La venta total de las cuotas de Abril-Civita se realizó en junio de 1977.

87 Mazzuca, 1991: 366. Celulosa Argentina, fundada en 1929, luego se había fundido con la Fabril Financiera. 
Angelo Rizzoli, en cambio de las ventajosas condiciones obtenidas en el negocio gracias a la mediación de Gelli, se compromete a «contribuire con tutti i suoi mezzi a migliorare la deteriorata immagine argentina in Italia e, nell'ambito delle sue possibilità, nel resto d'Europa» ${ }^{88}$. En efecto, despidiendo al corresponsal del periódico Corriere della Sera, Gian Giacomo Foà, la editorial Rizzoli, proprietaria del periódico hace que dejen de llegar noticias negativas desde Buenos Aires sobre la guerra sucia de la dictadura. «Per il Corriere è come se l'Argentina quasi non esistesse. Solo articoli rassicuranti in punta di penna» ${ }^{89}$.

\section{CONCLUSIÓN}

El caso de Cesare Civita y de la editorial Abril me parecen confirmar la importancia de las redes en la historia de la emigración. Cesare Civita y su familia, como los judíos italianos (más de mil) emigrados a Argentina a causa de la persecución racial, gracias a un rico tejido de relaciones, transformaron el exilio de «destierro» a «transtierro»" ${ }^{90}$, como sugiere el filósofo español José Gaos.

No se desarraigaron, sino que lograron reconstruir con éxito sus vidas y carreras profesionales. Desafiaron la susceptibilidades del nacionalismo argentino y también el antisemitismo latente que, en algunas coyunturas, afloraba violentamente en la sociedad. Aportaron nuevas ideas, nuevos proyectos, cambiaron con su trabajo la Argentina de posguerra.

El libro de María Eleonora Smolensky y Vera Vigevani Jarach recoge los testimonios de estos migrantes, y muestra que - aun cuando muchos de éstos volvieron a Italia, cuando fue posible - el vínculo que habían establecido con Argentina resultó fuerte: «la recuperación de los recuerdos italianos no lograría disipar la nostalgia de los años argentinos $\rangle^{91}$. El transnacionalismo fue y siguió siendo para ellos una experiencia fundamental.

Desde el punto de vista de la historia de la empresa el caso de Abril sugiere otras consideraciones. Las ventajas de una estructura familiar y la disponibilidad de un capital social que le brindaban los muchos contactos en países dife-

$88 \ll . .$. contribuir con todos sus medios para mejorar la deteriorada imagen argentina en Italia y, en el ámbito de sus posibilidades, en el resto de Europa», Silj, 1994: 218.

89 «Para el Corriere es como si la Argentina casi no existiera. Sólo artículos tranquilizadores y remilgados», Mazzuca, 1991: 391. Ya en 1981 Rizzoli reestructuró la Abril que había empezado bien, pero luego cayó en una grave crisis.

90 Faber, 2002: 212-215.

91 Smolensky y Jarach, 1999: 253. 
rentes fueron funcionales al desarrollo de la sociedad. También el capital físico se halló en el ambiente de amigos, compatriotas, en la business community. La internacionalización de la empresa siguió canales semejantes y se valió de las mismas redes étnicas, amistosas, profesionales. Sin embargo, a un cierto punto, cuando se hizo necesario dar un paso más, es decir, intentar controlar todo el ciclo productivo, a través de un proceso de integración que pasara de la producción de papel a la prensa, a la distribución, fue necesario apoyarse en la intervención pública. Este paso implicaba una negociación con el poder político que se reveló difícil y, finalmente, imposible.

La relación de Abril con la política había sido una relación distante y desconfiada en los primeros años y sobre todo durante los primeros dos gobiernos de Perón. Desde el punto de vista de la producción, sus tebeos, libros para niños y fotonovelas no constituían (o por lo menos todavía no se los percibía como) un potencial instrumento para influir en las elecciones políticas y culturales de los ciudadanos. Es más, un tebeo «nacionalizado» y una prensa femenina de evasión, que alentaba los roles y valores tradicionales de las mujeres no debía de suscitar excesivos temores en el Gobierno. Sin embargo, Abril había dado asilo político a la oposición antiperonista y a intelectuales simpatizantes socialistas y comunistas: esto cristalizó contra la editorial hostilidades y temores, tanto entre peronistas como entre militares.

Durante la breve temporada democrática entre 1955 y 1966, Abril amplió sus productos de manera que con una prensa femenina moderna y con las revistas de actualidad llegó a tocar ámbitos más expuestos a la tentación de censura por parte del poder político. La editorial mantuvo y desarrolló en esos años su característica de catalizador de intelectuales de oposición, abriéndose a las novedades culturales de la época.

Desde el arte pop al psicoanálisis sus revistas ponían de manifiesto un clima cultural en fermento, que tenía en el Instituto Di Tella su centro propulsor $^{92}$. Muy pronto, sin embargo, las críticas al estilo de las publicaciones de Abril comenzaron a provenir no sólo de los sectores tradicionalistas y conservadores, sino también desde los sectores de la izquierda radical y antiimperialista, hostiles hacia la cultura yanqui ${ }^{93}$.

92 King, 1985; Plotkin, 2003: 12-130. Después de 1968 los artistas del Di Tella fueron criticados por la nueva izquierda como «cultores de un arte lúdico, despolitizado, elitista...». Longoni y Mestman, 1999: 242.

93 Al final de los sesenta se difunde el «antiimperialismo cultural», que encuentra un ejemplo significativo en el libro de 1971 de Ariel Dorfman y Armand Mattelart, Para leer el Pato Donald. 
El golpe de Estado de 1966 inauguró un período de «intolerancia en el campo cultural, la sospecha hacia la actividad artística e intelectual, la persecución a la militancia política en general y a la izquierda en particular» ${ }^{94}$. Se vieron afectadas también las editoriales, particularmente la universitaria Eudeba. Tal como antes, Abril volvió a ser un puerto seguro para periodistas caídos en desgracia: cuando se clausuró la revista Primera Plana muchos colaboradores pasaron a Panorama $^{95}$.

Desde 1966 a 1973 para Abril la distancia del poder e incluso la fronda dejaron lugar, como hemos visto, a un intento de acercamiento que respondía a la necesidad de crecer que tenía la editorial invirtiendo en el sector clave de la producción de papel para periódicos. La posibilidad de explotar las medidas destinadas a favorecer una industria nacional en un sector básico implicó a Abril en un juego peligroso en que diferentes intereses económicos y políticos chocaban violentamente. El regreso del peronismo al poder puso fin a las ventajas adquiridas a raíz de la cercanía a los Gobiernos militares de los años anteriores.

Con Isabel Perón y luego con el nuevo régimen militar en 1976, la hostilidad del Gobierno hacia Abril, considerada demasiado poderosa en el campo de la información y demasiado hospitalaria hacia la oposición "subversiva», se hizo dramáticamente evidente y Cesare Civita se vio obligado a abandonar el país y vender la sociedad.

La evolución diferente de la editorial Abril brasileña (que aquí no tratamos) en comparación a su gemela argentina puede constituir la contraprueba de la importancia del contexto económico y político en que una empresa familiar obra. Abril brasileña conoció a partir de los años sesenta en adelante un proceso de rápido desarrollo ininterrumpido que la convierte hoy en una de las más importantes editoriales latinoamericanas ${ }^{96}$. Se puede hipotizar que haya podido aprovechar, aun ante las dificultades vinculadas a las limitaciones de la libertad de prensa, la ventaja de mejores relaciones con el poder político. El régimen militar brasileño fue probablemente para los empresarios un interlocutor más estable y más hábil gestor de la economía que el argentino ${ }^{97}$.

Bárbara Civita recuerda la desesperación de su padre cuando debió dejar definitivamente la Argentina y vender Abril, una empresa eficiente y en pleno

94 De Sagastizábal 1995: 166.

95 Ulanowski, 2005: 280.

96 Véase el sitio de la Editora Abril: in http://www.centenariovictorcivita.com.br/.

97 Sería interesante también comparar el caso de la Abril argentina con el de la Mexabril, que se desarrolló en un contexto de estabilidad política y cercanía al poder. 
desarrollo. Para él era como volver a transitar acontecimientos ya vividos, encontrarse de nuevo frente a «una ripetizione di quello che era già accaduto nel $1938 »$.

El caso de la familia Civita y de la editorial Abril no tiene un final feliz. Se concluye, en efecto, con un destierro.

En su segundo exilio, después de 1976, los Civita compartieron el destino con tantos argentinos ${ }^{98}$. Trataron de reconstruir nuevamente su vida en otros países de América latina, en los Estados Unidos y en Europa. La editorial en manos de los nuevos propietarios, decayó rápidamente. Abril, empresa de exiliados italianos, había llegado a formar parte de la sociedad argentina y fue víctima de su crisis más dramática.

\section{BIBLIOGRAFÍA}

Aldrighi, Clara, La inmigración Judía italiana a Uruguay, 1997, mecanografiado.

Aguilar, Gonzalo, «Televisión y vida privada», Fernando Devoto y Marta Madero (directores), Historia de la vida privada en la Argentina, vol. 3, Buenos Aires, Taurus, 1999: 255-283.

Ajello, Nello, «Il settimanale di attualità», Valerio Castronovo y Nicola Tranfaglia, $L a$ stampa italiana del neocapitalismo, Bari Laterza, 1976: 173-250.

Baily, Samuel L., «Transnazionalismo e diaspora italiana in America Latina», Maddalena Tirabassi (ed.), Itinera. Paradigmi delle migrazioni italiane, Torino, Fondazione Giovanni Agnelli, 2005: 43-69.

Blanco, Alejandro, Razón y modernidad. Gino Germani y la sociología en la Argentina, Buenos Aires, Siglo XXI editores, 2006.

Bravo, Anna, Il fotoromanzo, Bologna, Il Mulino, 2003.

Brunoro, Gianni, «Il richiamo della Pampa», Gianni Brunoro y Roberto Reali (ed.), Magica America. Un'antologia fumettistica, Reggio Emilia, ANAFI, 2004a.

Brunoro, Gianni, «Cesare Civita «il nostro uomo all'Abril», Gianni Brunoro y Roberto Reali (ed.), Magica America. Un'antologia fumettistica, Reggio Emilia, ANAFI, 2004b.

Civita, Cesare, La mia vita, publicación reservada, 1987.

Cohen, Robin, «Reti di migranti transnazionali», Maddalena Tirabassi (ed.), Itinera. Paradigmi delle migrazioni italiane, Torino, Fondazione Giovanni Agnelli, 2005: 21-41.

98 Varios periodistas y trabajadores de la Abril se exiliaron y algunos fueron asesinados o desaparecidos. 
Cosse, Isabella, «Cultura y sexualidad en la Argentina de los sesenta: usos y resignificaciones de la experiencia transnacional», Estudios Interdisciplinarios de América Latina y el Caribe, 17/1 (Tel Aviv, 2006): 39-60.

Cosse, Isabella, «Los nuevos prototipos femeninos en los años 60 y 70: de la mujer doméstica a la joven "liberada"», Andrea Andújar, Débora D’Antonio, Karin Grammático, Fernanda Gil Lozano, María Laura Rosa y Valeria Pita, Historia, Género y Política en los 70, Buenos Aires, Editorial Luxemburg, en prensa.

Dantas Taveira Cabral, Eula, «Internacionalização da midia brasileira: análise das estratégias do Grupo Abril», www.intercom.org.br/papers/nacionais/2006/resumos/R1312-1.pdf -.

De Riz, Liliana, Historia argentina. La política en suspenso. 1966/1976, Buenos Aires, Paidós, 2000.

De Sagastizábal, Leandro, La edición de libros en la Argentina. Una empresa de cultura, Buenos Aires, Eudeba, 1995.

Editorial Abril, Una empresa argentina para América, Buenos Aires, 1973circa.

Eliot, Marc, Walt Disney. Il principe nero di Hollywood, Milano, Bompiani, 1993.

Faber Sebastian, Exile and Cultural Hegemony: Spanish Intellectuals in Mexico, 1939-1975, Nashville, Vanderbilt University Press, 2002.

Fanesi, Pietro R., Verso l'altra Italia. Albano Corneli e l'esilio antifascista in Argentina, Milano, Franco Angeli, 1991.

Fanesi, Pietro R., «Gli ebrei italiani rifugiati in America latina e l'antifascismo (19381945)», Storia e problemi contemporanei, VII/ 14 (Ancona, 1994): 23-36.

Ferretti, Gian Carlo, Storia dell'editoria letteraria in Italia-1945-2003, Torino, Einaudi, 2007.

Feijoo, María del Carmen y Nari, Marcela M.A., «Women in Argentina During the 1960s», Latin American Perspectives, 23/1, (Thousand Oaks, CA, 1996): 7-26.

Flores, Roberto, Fotonovela argentina, Buenos Aires, Asociación Argentina de Editores de Revistas, 1997.

Gabaccia, Donna R. y M. Ottanelli Fraser M. (eds.), Italian Workers of the World: Labor Migration and the Formation of Multiethnic States, Urbana (IL), University of Illinois Press, 2001.

Garruccio, Roberta, «Capitale sociale e capitale etnico. Una letteratura maturata a contatto con l'evidenza», Annali di Storia dell'Impresa, 11(Venezia, 2000): 445-471.

Gasparini, Juan, David Graiver. El banquero de los Montoneros, Buenos Aires, Grupo Editorial Norma, Buenos Aires, 2007.

Genovesi, Giovanni, La stampa periodica per ragazzi, Valerio Castronovo y Nicola Tranfaglia, La stampa italiana del neocapitalismo, Bari Laterza, 1976: 377-444. 
Germani, Ana Alejandra, Gino Germani. Del antifascismo a la sociología, Buenos Aires, Taurus, 2004.

King, John, El Di Tella y el Desarrollo Cultural Argentino en la Década del Sesenta, Buenos Aires, Ediciones de Arte Gaglianone, 1985.

Longoni Ana y Mariano Mestman, «Vanguardia y revolución: acciones y definiciones por una "nueva estética" argentina, 1968», Alfredo Pucciarelli (ed.), La primacía de la política. Lanusse, Perón y la Nueva Izquierda en tiempos del GAN, Buenos Aires, Eudeba, 1999: 235-264.

Lussana, Carolina, 1946: la prima frontiera. Dalla corrispondenza argentina di Agostino Rocca, Bergamo, Fondazione Dalmine, 1999.

Mazzuca, Alberto, La Erre verde. Ascesa e declino dell'impero Rizzoli. Storia di una dinastia italiana e della guerra per il «Corriere», Milano, Longanesi, 1991.

Mutti, Antonio, Capitale sociale e sviluppo. La fiducia come risorsa, Bologna, Il Mulino, 1998.

Piselli, Fortunata, «Reti sociali e comunicative», Fortunata Piselli (ed.), Reti. L'analisi di network nelle scienze sociali, Roma, Donzelli editore, 1995: VII-LXXIII.

Plotkin, Mariano Ben, «Tell me your dreams: Psychoanalysis and popular culture in Buenos Aires, 1930-1950», The Americas, 55/4 (Berkeley CA,1999): 601-629.

Plotkin, Mariano Ben, Freud en las Pampas, Buenos Aires, Sudamericana, 2003.

Ramos, Julio A., Los cerrojos a la prensa, Buenos Aires, Julio A. Amfin, 1993.

Rein, Raanan, Argentina, Israel y los judios. Encuentros y desencuentros, mitos y realidades, Buenos Aires, Ediciones Lumiere, 2001.

Sarfatti, Michele, Gli ebrei nell'Italia fascista. Vicende, identità, persecuzione, Torino, Torino Einaudi, 2007.

Scarzanella, Eugenia (comp.), Fascistas en América del Sur, Buenos Aires, Fondo de Cultura Económica, 2007.

Scarzanella, Eugenia, «Fotonovelas y revistas femeninas: inmigración italiana en Argentina y consumo cultural en la época del peronismo», Actas XV Congreso Internacional de AHILA, Leiden, 26-29 agosto 2008, en prensa.

Schneider, Arnd, «Organizing Ethnicity: Three Episodes in the Politics of Italian Associations in Argentina, 1947-1989», Canadian Journal of Latin American and Caribbean Studies, 25/50 (Montréal QC, 2000): 195-228.

Schvarzer, Jorge, «Expansión, maduración y perspectivas de las ramas básicas de procesos en la industria argentina. Una mirada ex post desde la economía política», Desarrollo Económico, 38/131 (Buenos Aires, 1993): 377-402.

Senkman, Leonardo, Argentina, la segunda guerra mundial y los refugiados indeseables, 1933-1945, Buenos Aires, Grupo Editor Latinoamericano, 1991. 
Silj, Alessandro, Malpaese. Criminalità, corruzione e politica nell'Italia della prima Repubblica, Roma, Donzelli, 1994.

Smolensky, Eleonora María y Vera Vigevani Jarach, Tantas voces, una historia. Italianos judios en la Argentina, 1938-1948, Buenos Aires, Temas Grupo Editorial, 1999.

Spivacow, Boris, Memoria de un sueño argentino. Entrevistas de Delia Maunás, Buenos Aires, Ediciones Colihue, 1995.

Ulanovsky, Carlos, Paren las rotativas. Diarios, revistas y periodistas (1920-1969), Buenos Aires, Emecé, 2005.

Ulanovsky, Carlos, Paren las rotativas. Diarios, revistas y periodistas (1970-2000), Buenos Aires, Emecé, 2005.

Vezzetti, Hugo, «Las promesas del psicoanálisis en la cultura de masas», Fernando Devoto y Marta Madero (comp.), Historia de la vida privada en la Argentina. La Argentina entre multitudes y soledades. De los años treinta a la actualidad, vol. 3, Buenos Aires, Taurus, 1999: 173-197.

\section{BETWEEN TWO EXILES: CESARE CIVITA, AN ITALIAN PUBLISHER IN BUENOS AIRES, FROM WORLD WAR II TO THE MILITARY DICTATORSHIP (1941-1976)}

This paper deals with the history of an Argentinian publishing house called Editorial Abril, which was founded in 1941 by Cesare Civita, a Jewish immigrant who left Italy after the «race laws» approval. Abril published cartoons (Donald Duck), photo novels (Idilio), women's magazines (Claudia) and news magazines (Panorama). Abril was a family business which knew how to use a wide relation network in Argentina, Italy and the United States. The history of this publishing house ends with Cesare Civita's new exile in 1976. The material used includes file sources, testimonies, journals and books.

KEY WORDS: Argentina, Italian immigration, exile, publishing house of popular magazines. 